RJPSS Sept. 2020 Vol. XLV No.2, ISSN: (P)0258-1701 (e)2454-3403 Impact Factor: 7.717

https://doi.org/10.31995/rjpss.2020.v45i01.026

\title{
A Study on Impact of Hypnotherapy on Traumatic Experiences of Children in Child Care Institution of Indore City
}

\author{
Deepa Jain \\ Research Scholar, \\ dipaajain@gmail.com \\ Dr. Saroj Kothari \\ Professor and Head, Dept. of Psychology, \\ Government M.L.B.P.G. College, Indore,
}

\begin{abstract}
Background:

The purpose of the present study was to investigate the effect of hypnotherapy on the traumatic experiences of institutionalized children.

Methodology:

To achieve the purpose of the study twenty-three girl child was selected as a sample from Child Care Institute, Indore, India during the year 2019. The subject's age ranges from 10 to 18 years. The selected students were divided into two groups consists of 14 children as the experimental group and 9 as the control group. The experimental group underwent a planned hypnotherapy session for seven weeks. The control group was not taking part in any intervention during the study. Trauma was taken as a criterion variable in this study. The selected subjects were tested on Trauma was measured through the Childhood Trauma Screening questionnaire(CTSQ) by Justin A. Kenardy, S. H. Spence, A. C. Macleod. (Kenardy, Spence, \& Macleod, 2006). Pre-test was taken before the training period and the post-test was measured immediately after the five weeks training period. Statistical technique Wilcoxon was used to analyzing the means of the pre-test and post-test data of the experimental group and control group.
\end{abstract}

Result:

The results revealed that there was a significant difference found in the criterion variable. The difference is found due to planned hypnotic sessions of hypnotic induction, using progressive relaxation and breathing awareness followed by guided imagination and a fivestep approach of ego strengthening and ego enhancement given to the experimental group on trauma when compared to the control group. Therapy also aims to teach self-hypnosis, to enable patients to manage their own symptoms.

Conclusion:

Prevalence of psychiatric disturbance and reporting of somatic symptoms among children living in an institution is very high. Keywords: Trauma, Hypnotherapy, Psychiatric disß2]
Reference to this paper should be made as follows:

Received: 09.08.2020

Approved: 29.09.2020

Deepa Jain,

Dr. Saroj Kothari

Study on Impact of

Hypnotherapy on

Traumatic Experiences

of Children in Child

Care Institution of Indore City

Article No. 26

RJPSS Sept. 2020,

Vol. XLV No. 2,

pp. 221-230

Online available at:

https://anubooks.com/rjpss2020-vol-xlv-no-2/

https://doi.org/10.31995/ rjpss.2020.v45i01.026 
Study on Impact of Hypnotherapy on Traumatic Experiences of Children in Child Care....... Deepa Jain, Dr. Saroj Kothari

\section{Introduction:}

Trauma is defined as a sudden, potentially deadly experience, often leaving lasting, troubling memories. One in four children experiences a traumatic event by the time they are 18 years old. For institutional children, trauma is a predisposing factor for mental illness.

Clinical Hypnosis is one of the alternative therapies and often most effective when it is combined with other (non-hypnotic) interventions.

According to the UNICEF 2012, there are more than 25 million orphans or abandoned and about 44 million destitute children in India.[18]

The relationship between trauma and mental illness was first investigated by the neurologist Jean-Martin Charcot, who was working with traumatized women in the Salpetriere hospital. Charcot was the first to understand that the origin of hysterical symptoms was not physiological but rather psychological in nature. $\mathrm{He}$ notes that traumatic events could induce a hypnotic state in his patients (van der Kolk, Weisaeth, \& van der Hart, 1996, p. 50). Charcot hypnotized his patient and then helped to remember their trauma (Herman, 1992). He found that through hypnosis and abreaction, or exposure to the traumatic memories, patients' symptoms could be alleviated (van der Kolk, Weisaeth, et al., 1996)

The National Child Traumatic Stress Network (NCTSN) defines complex trauma as children's experiences of multiple traumatic experiences that occur within the caregiving system - the social environment that is supposed to be a source of safety and stability in a child's life (Cook, Spinazzola, \& Ford, 2005). Survivors of complex trauma experience many adverse consequences which include psychological, social, and biological challenges throughout their lifetime (van der Kolk, Roth, Pelcovitz, Sunday, \& Spinazzola, 2005). To counteract these affect the individual's physical and emotional systems must be considered with equal importance to achieve long-term and meaningful phycological growth (Brodie \& Lobel, 2012).

Repeated suffering causes ego weakness which leads to a lack of selfconfidence, lack of decision power, lack of concentration, negative thinking, emotional instability, and lack of consistency. The call for a holistic understanding

of the developmental impact of chronic trauma points towards the mind-body connection as an important factor of treatment (Odgen, Minton, Pain, \& van der Kolk, 2006). Hypnotherapy is used as an intervention to promote and incorporate the whole person rather than focusing on isolated symptoms. 
RJPSS Sept. 2020 Vol. XLV No.2, ISSN: (P)0258-1701 (e)2454-3403 Impact Factor: 7.717

https://doi.org/10.31995/rjpss.2020.v45i01.026

Hypnotherapy has been used with children for more than 200 years. Dr.Gardner and Dr. Olness together published the first edition of hypnosis and hypnotherapy with children (Gardner \& Olness, 1981). Daniel P. Kohen, a pediatrician was practicing hypnotherapy in children since 1977 (Kohen \& Olness, 2012). Hypnotherapy is a useful and efficient strategy, when used appropriately with early adolescents. A comparative study in the American Health Magazine, 2007, shows hypnosis as an effective modality. The results of various treatments show Psychoanalysis: $38 \%$ recovery after 600 sessions. Behavior therapy: $72 \%$ recovery after 22 sessions. Hypnotherapy: 93\% recovery after 6 sessions. Therapeutic use of hypnosis is becoming popular today in the management of psychosomatic disorders, habit disorders, neurotic conditions, psychosexual problems, substance abuse, and pain management. It is also used for stress management, lifestyle management, and for improving performance in sports and studies.

In 1979, a review of the literature was done on obesity and hypnosis (Thurman \& Joan, 1979), in which it was concluded that although there is evidence that hypnosis may have a role in the treatment of obesity, well-designed research studies are needed to establish the extent of its usefulness. (Crasilneck \& Hall, 1975)Crasilneck and Hall had combined hypnosis with the behavioral approach, or ego state therapy (Torem, 1986) and concluded hypnotherapy as a rapid and cost-effective form of treatment for eating disorders.

George K Ganaway 1995 in a study on hypnosis "Childhood trauma and dissociative identity disorder; toward an interactive theory" demonstrated the importance of adopting experimental and clinical research in the diagnosis and treatment of severe dissociative syndromes (Ganaway, 1995). In an article by Richard P. Kluft. on hypnotherapy of childhood multiple personality disorder, it was found that in all cases hypnosis was used and observations suggest that adult MPD may be prevented by proper identification and early treatment of children (Kluft, 1985).

A meta-analysis was conducted by Erich Flammer and Assen Alladin (Flammer \& Alladin, 2007) with 21 randomized, controlled clinical studies to evaluate the efficacy of hypnosis in psychosomatic disorders. The study clearly indicates hypnotherapy is highly effective in the treatment of psychosomatic disorders.

A study of three case reports by Arnold Miller on the disruptive impact of anxiety on performance showed that when hypnotherapy is used as an intervention(Miller, 1986). The result shows a restoration of anxiety-free functioning. 
Study on Impact of Hypnotherapy on Traumatic Experiences of Children in Child Care.........

Deepa Jain, Dr. Saroj Kothari

In a study on individual and group hypnotherapy in the treatment of refractory irritable bowel syndrome (IBS) of 33 patients with refractory IBS were treated with four 40 mins sessions of hypnotherapy over 7 weeks. Among these 20 patients showed improvements, 11 of whom lost all their symptoms (Harvey, Gunary, \& Hinton, 1989). An article by Etzel Carden on hypnosis in the treatment of trauma, but not fully supported, officious intervention reveals that hypnotic techniques for the treatment of post-traumatic conditions were often used by the clinical pioneers of the end of the $19^{\text {th }}$ century and by military therapists for treating soldiers during the $20^{\text {th }}$ century.

Although very few studies on the efficacy of hypnosis for post-traumatic disorders have been done, yet it is considered that hypnosis can be easily integrated into therapies for treating traumatized clients as studies show that PTSD individuals have high hypnotisability. It was also found that hypnotic techniques may help modulate and integrate memories of trauma(Carden, 2008). It was found that hypnotherapy is effective in the treatment of chronic tension-type headache and anxiety scores(Melis \& Rooimans, 1991). In a case study of a 45-year-old person suffering from a schizophrenic disorder of the depressed type, treatment through rational stage directed hypnotherapy was done. Results showed improvement in the client's thought processes and rational thinking, his anxiety was considerably diminished, and mood disturbance was more controlled(Reardon, Tosi, \& Gwynne, 1977).

All these researches lead to the conclusion that various horrible external events in childhood create a poor mental condition.

\section{Rationale of the study}

Although, child maltreatment has been legally recognized in the United States since 1655, cases of child abuse and neglect continue to be reported (New World Encyclopedia, 2013). Childhood trauma leads to psychiatric disorders of adolescence and adulthood. These complications may be of any nature, biological, social, or psychological. And more than that there may be both psychosomatic and somatopsychic. Hypnotherapy is a holistic approach to wellness, in which psychological and biological systems are viewed as interconnected and is a more productive method to treat PTSD, anxiety, depression, somatic symptoms, insomnia, social dysfunction.

Hypnotherapy is a better solution to treat emotionally disturbed children as children often do not tell about incidences for many reasons such as stigmatization, fear, shame, guilt, or self-blame about the event. Hypnotherapy is useful for children 
RJPSS Sept. 2020 Vol. XLV No.2, ISSN: (P)0258-1701 (e)2454-3403 Impact Factor: 7.717

https://doi.org/10.31995/rjpss.2020.v45i01.026

as it works on a subconscious level. According to the National Center of Mental Health Promotion, $60 \%$ of adults report experiencing abuse or other difficult family circumstances during childhood which in turn increases the risk of health problems (Childhood Trauma and Its Effect on Health Development, 2012). Hence it is time to address the needs and intervention for child survivors of complex trauma.

\section{MATERIALS AND METHODS}

A descriptive study design was adopted and a convenient sampling technique was employ. The study has been done in an institutional home of urban city Indore. The sample consists of 23 teenage girls in the age group of 10-18 years residing in a Child Care Institution. Case study has also been taken of children selected for the study. Children with a history of traumatic life events between the age of 10-18 years, from CCI, has been taken as an experimental and control group, as a sample for the study. Out of these 14 are taken as experimental groups and 9 as a control group. The study was conducted over a period of three months from November 19, 2018- February 19, 2019. Approval for conducting the study was obtained from the Institutional Head. As the children are under 18 years hence permission from the organization caregiver is taken. The nature and purpose of the study and the procedure involved were explained to the study subjects and their consent was obtained after assuring them of utmost confidentiality.

For the assessment of trauma symptoms, Child Trauma Screening Questionnaire (CTSQ) was used. The CTSQ assesses 10 items, for reexperiencing (5 items) and hyperarousal symptoms (5 items). The questionnaire is translated in Hindi for their understanding as it is a self -reporting type. The responses recorded are in the form of yes (scored 1 ) or no (scored 0 ) to whether they have experienced the symptoms since the event. A child scoreless than 4 on a scale of 10 will be considered under trauma.

Two groups of before-after experimental designs are used as the research design. For statistical analysis, the Wilcoxon test is used. For data collection children were given a trauma screening tool before and after the intervention. Hypnosis is used as an intervention. To understand the susceptibility a Hypnotic Susceptibility 
Study on Impact of Hypnotherapy on Traumatic Experiences of Children in Child Care........

Deepa Jain, Dr. Saroj Kothari

assessment was done by eye-roll test on 30 children. Out of these 23 children show good susceptibility. Hypnosis is applied to 14 children as part of the intervention and 9 children were treated as a control group.

\begin{tabular}{|l|l|l|}
\hline Screening & $\begin{array}{l}\text { Experimental } \\
\text { Group }\end{array}$ & $\begin{array}{l}\text { Control } \\
\text { Group }\end{array}$ \\
\hline $\begin{array}{l}\text { Hypnotic susceptibility assessment } \\
\text { was done by eye uproll test }-30 \\
\begin{array}{l}\text { After the susceptibility test, 24 } \\
\text { children show good susceptibility. }\end{array}\end{array}$ & 15 & 9 \\
\hline
\end{tabular}

\section{Treatment Plan:}

Case history will be taken for all the children taken for the sample.

Planned therapy session for 5 weeks:

\begin{tabular}{|ll|l|l|}
\hline Session & Duration & Frequency \\
\hline 1. & Session for breathing awareness & 15 mins & Every day for 2 week \\
\hline $\begin{array}{l}\text { 2. } \\
\begin{array}{l}\text { Session for Progressive Muscular } \\
\text { Relaxation passive }\end{array}\end{array}$ & 15 mins & Every day for 2 week \\
\hline 3. & Session for guided/unguided imagination & 20 mins & Every alternate day for 2 week \\
\hline 4. & Session for ego strengthening & 25 mins & Every alternate day for 2 week \\
\hline 5. & Session for ego enhancement & 25 mins & Every alternate day for 2 week \\
\hline
\end{tabular}

After the pretest, planned hypnotic sessions will be administered on the experimental group for a duration of 7 weeks. After 7 weeks duration, the posttest will be administered on both experimental and control groups to assess the effects of hypnosis on symptoms of trauma.

\section{Inclusion criteria}

Children in the age group of 8-18 years residing in an institution.

\section{Exclusion criteria}

Children not qualifying trauma screening tests. 
RJPSS Sept. 2020 Vol. XLV No.2, ISSN: (P)0258-1701 (e)2454-3403 Impact Factor: 7.717

https://doi.org/10.31995/rjpss.2020.v45i01.026

\section{Result}

\section{EXPLANATION OF STATISTICAL RESULTS}

Descriptive Statistics[Table -1 IScore of trauma before and after therapy on experimental and
control group
\begin{tabular}{|ll|r|r|r|r|r|}
\hline Group & $\mathrm{N}$ & Mean & $\begin{array}{c}\text { Std. } \\
\text { Deviation }\end{array}$ & Minimum & Maximum \\
\hline $\begin{array}{l}\text { Experimental } \\
\text { group }\end{array}$ & $\begin{array}{l}\text { Score of } \\
\text { Childhood } \\
\text { Trauma before the } \\
\text { therapy } \\
\text { Score of } \\
\text { Childhood } \\
\text { Trauma after the } \\
\text { therapy }\end{array}$ & 14 & 6.50 & 1.653 & 10 & \\
\hline $\begin{array}{l}\text { Score of } \\
\text { Childhood } \\
\text { Trauma before the } \\
\text { therapy } \\
\text { Score of } \\
\text { Childhood } \\
\text { Trauma after the } \\
\text { therapy }\end{array}$ & 9 & 2.86 & 1.460 & 1 & \\
\hline
\end{tabular}

Above table-1 shows us the descriptive statistics of our data by groups. As we can see the mean score after the therapy in the experimental group is much lower than the mean score before the therapy. This shows us a direction in which our result is going. That is, it is indicating that the level of trauma is decreasing after the therapy session. And that difference in the control group is less.

Ranks[Table-2]

\begin{tabular}{|c|c|c|c|c|c|}
\hline Group & & & $\mathrm{N}$ & Mean Rank & Sum of Ranks \\
\hline $\begin{array}{l}\text { Experimental } \\
\text { group }\end{array}$ & $\begin{array}{l}\text { Score of Childhood } \\
\text { Trauma after the } \\
\text { therapy - Score of } \\
\text { Childhood Trauma } \\
\text { before the therapy }\end{array}$ & $\begin{array}{l}\text { Negative Ranks } \\
\text { Positive Ranks } \\
\text { Ties } \\
\text { Total }\end{array}$ & $\begin{array}{r}14^{\mathrm{a}} \\
0^{\mathrm{b}} \\
0^{\mathrm{c}} \\
14\end{array}$ & $\begin{array}{r}7.50 \\
.00\end{array}$ & $\begin{array}{r}105.00 \\
.00\end{array}$ \\
\hline Control Group & $\begin{array}{l}\text { Score of Childhood } \\
\text { Trauma after the } \\
\text { therapy - Score of } \\
\text { Childhood Trauma } \\
\text { before the therapy }\end{array}$ & $\begin{array}{l}\text { Negative Ranks } \\
\text { Positive Ranks } \\
\text { Ties } \\
\text { Total }\end{array}$ & $\begin{array}{l}6^{\mathrm{a}} \\
0^{\mathrm{b}} \\
3^{\mathrm{c}} \\
9\end{array}$ & \begin{tabular}{r|}
3.50 \\
.00
\end{tabular} & $\begin{array}{r}21.00 \\
.00\end{array}$ \\
\hline
\end{tabular}


Study on Impact of Hypnotherapy on Traumatic Experiences of Children in Child Care........ Deepa Jain, Dr. Saroj Kothari

\section{Table-3 Test Statistics}

\begin{tabular}{|c|c|c|}
\hline Group & & $\begin{array}{c}\text { Score of Childhood Trauma after the } \\
\text { therapy - Score of Childhood Trauma } \\
\text { before the therapy }\end{array}$ \\
\hline $\begin{array}{l}\text { Experimental } \\
\text { group }\end{array}$ & $\begin{array}{l}\text { Z } \\
\text { Asymp. Sig. } \\
\text { (2-tailed) }\end{array}$ & $\begin{array}{r}-3.318^{a} \\
.001\end{array}$ \\
\hline Control Group & $\begin{array}{l}\text { Z } \\
\text { Asymp. Sig. } \\
\text { (2-tailed) }\end{array}$ & $\begin{array}{r}-2.271^{\mathrm{a}} \\
.023\end{array}$ \\
\hline
\end{tabular}

a. Based on positive ranks.

b. Wilcoxon Signed Ranks Test

This table-3 shows the significance level of the Wilcoxon sum rank test which we can see that is significant on the level of 0.01 in the experimental group. And the difference which we have got is significant at the 0.05 level but not on 0.01 level.

\section{Discussion}

The study is a qualitative investigation to better understand the trauma experiences of institutionalized children. The goal of the study was to understand the efficacy of clinical hypnosis as an intervention in the traumatic experience of institutionalized children.

Above table-1 shows us the descriptive statistics of our data by groups. As we can see the mean score before therapy was 6.50 and it becomes 2.86 after the therapy in the experimental group, which is much lower than the mean score before the therapy. This shows us a direction in which our result is going. That is, it is indicating that the level of trauma is decreasing after the therapy session. And in the control group mean score before therapy was 4.67 and it becomes 3.78 after the therapy, which is not much lower than the mean score before the therapy, so it is clear that the difference in the control group is less.

\section{Conclusion}

In conclusion, findings from this study are additional in existing research, which suggests that institutionalized children faced a substantial range of problems, which turn out in form of traumatic experiences. This study also suggests that, most of the children here face traumatic symptoms like experiencing thought and memory 
RJPSS Sept. 2020 Vol. XLV No.2, ISSN: (P)0258-1701 (e)2454-3403 Impact Factor: 7.717

https://doi.org/10.31995/rjpss.2020.v45i01.026

of the past event, experience stomach ache, sweating and dizziness when reminded of a past event, lose their temper, difficulty in paying attention, and psychiatric problems like feeling nervous, tense, worried, difficulty in making decisions, and feel like they are unable to play a useful part in their life. This suggests that they are not only deprived of basic needs but also psychological needs of recognition. Belief of worthlessness continuously disempowers them. Effective intervention with a proper assessment of problems and follow up should be the priority of policymakers. The caregivers of the institutions should be psycho-educated about the psychological needs of these children. They should have an empathetic and non-judgmental attitude towards these children. With the help of emotional support, love, and care only we can help them in overcoming their problems.

\section{Limitations}

A limitation of the study was the relatively small sample size. For this reason, these findings cannot be generalized to the broader community based on this study alone.

\section{References}

1. Brodie, J. A., \& Lobel, E. E. (2012). Dance and Somatics: Mind-Body Principles of Teaching and Performance. Library of Congress Cataloging in Publication Data.

2. Carden, E. (2008). Hypnosis in the treatment of trauma: A promising, but not fully supported, efficacious intervention. International Journal of Clinical and Experimental Hypnosis, 48(2), 225-238. DOI:10.1080/00207140008410049

3. Childhood Trauma and Its Effect on Health Development. (2012, July). National Center for Mental Health Promotion and Youth Violence Prevention.

4. Cook, A., Spinazzola, J., \& Ford, J. (2005). Complex trauma in children and adolescents. Psychiatric Annals, 35(5), 390-398. DOI:10.3928/0048571320050501-05

5. Crasilneck, H. B., \& Hall, J. A. (1975). Clinical Hypnosis: Principles and applications (1st ed.). Grune and Stratton. Retrieved 2019

6. Flammer, E., \& Alladin, A. (2007). The Efficacy of Hypnotherapy in the Treatment of Psychosomatic Disorders: Meta-analytical Evidence. International Journal of Clinical and Experimental Hypnosis, 55(3), 251-274. DOI:10.1080/ 00207140701338696

7. Ganaway, G. K. (1995). Hypnosis, childhood trauma, and dissociative identity disorder: Toward an integrative theory. International Journal of Clinical and Experimental Hypnosis, 43(2), 127-144. DOI:10.1080/00207149508409957 
Study on Impact of Hypnotherapy on Traumatic Experiences of Children in Child Care.........

Deepa Jain, Dr. Saroj Kothari

8. Gardner, G. G., \& Olness, K. (1981). Hypnosis and hypnotherapy with children. Grune and Stratton, Incorporated.

9. Harvey, R. F., Gunary, R. M., \& Hinton, R. A. (1989). Individual and group hypnotherapy in the treatment of refractory irritable bowel syndrome. The Lancet, 333(8635), 424-425. DOI:10.1016/S0140-6736(89)90013-5

10. Kenardy, J. A., Spence, S. H., \& Macleod, A. C. (2006). Screening for posttraumatic stress disorder in children after an accidental injury. Pediatrics, $118(3), 1002-1009$.

11. Kluft, R. P. (1985). Hypnotherapy of childhood multiple personality disorder. American Journal of Clinical Hypnosis, 27(4), 201-210. DOI:10.1080/ 00029157.1985 .10402608

12. Kohen, D. P., \& Olness, K. (2012). Hypnosis and Hypnotherapy with Children (Vol. IV). Newyork. DOI:10.4324/9780203830130

13. Melis, P. M., \& Rooimans, W. (1991). Treatment of chronic tension type headache with hypnotherapy: a single blind time controlled study. Headache : The journal of head and face pain, 31(10), 686-689. DOI:10.1111/j.15264610.1991.hed3110686.

14. Miller, A. (1986). Brief reconstructive hypnotherapy for anxiety reactions: Three case reports. American Journal of Clinical Hypnosis, 28(3), 138-146. DOI:10.1080/00029157.1986.10402644

15. Odgen, P., Minton, K., Pan, C., \& van der Kolk, B. (2006). Trauma and the body: A sensorimotor approach to psychotherapy. New York: W.W. Norton.

16. Reardon, J. P., Tosi, D. J., \& Gwynne, P. H. (1977). The treatment of depression through rational stage directed hypnotherapy: A case study. Psychotherapy Theory, Research, and Practice, 14(1), 95-103. DOI:10.1037/h0087498

17. Thurman, M., \& Joan, R. (1979). Obesity and Hypnosis: A Review of the Literature. The American journal of clinical hypnosis, 22(1), 3-7. DOI:10.1080/ 00029157.1979.10403994

18. Torem, M. S. (1986). Dissociative states presenting as an eating disorder. American Journal of Clinical Hypnosis, 29(2), 137-143. DOI:10.1080/ 00029157.1986.10402697

19. van der Kolk, B. A., Roth, S., Pelcovitz, D., Sunday, S., \& Spinazzola, J. (2005). Disorders of extreme stress: The empirical foundation of a complex adaptation to trauma. Journal of Traumatic Stress, 18(5), 401-408. DOI:10.1002/jts.20047 